\title{
Silvia Marina Arrom. Voluntarios por una causa. Género, fe y caridad en México desde la Reforma hasta la Revolución.
}

Ciudad de México: Centro de Investigaciones y Estudios Superiores en Antropología Social, 2017, 340 pp.

Marina Téllez González^

E ste libro es una compilación de revelaciones. Silvia Marina Arrom reconoce el - nacimiento de su inquietud por historiar el origen y desarrollo de la Sociedad de San Vicente de Paúl en México en una anécdota familiar. A sus ojos, la vida secreta de sus abuelas le develó un problema histórico omitido por la historiografía nacionalista y liberal del siglo XIX mexicano, por los investigadores de la asistencia social, de la iglesia y hasta por la renovadora historia con perspectiva de género. La historia que cuantitativamente Arrom elabora rescata del olvido las actividades de centenares de hombres y mujeres laicos, de clase media y alta, comprometidos con su sociedad y con una idea paternalista-católica de ayuda a los pobres.

De entrada, la investigación tiene dos aportaciones historiográficas importantes. En primer lugar, Voluntarios por una causa contradice el discurso histórico de la segunda mitad del siglo XIX que afirma la derrota de la Iglesia, la desarticulación de su maquinaria institucional y la dispersión de su base social durante la República restaurada. La autora demuestra, al indagar sobre los avatares de las conferencias masculinas y femeninas de la Sociedad de San Vicente Paúl desde 1840, que ambas — según sus propios informes — vivieron su mejor momento durante los años 1867 y 1875; la época más radical del liberalismo mexicano. En segundo lugar, Arrom complementa y matiza la historiografía que renovó y continúa innovando los estudios del siglo XX mexicano, al ensayar acercamientos con una perspectiva más social que institucional. Esta historiografia a la que la autora debe mucho y de la que forma parte fue la primera en retomar el tema y revalorar la participación de la Iglesia mexicana en los procesos históricos de los siglos XIX y XX.

Sin duda, las investigaciones de autores como Jorge Adame Goddard, Manuel Ceballos, Roderic Ai Camp, o más recientemente Gabriela Aguirre Cristiani,

* Estudiante del doctorado en Historia, El Colegio de México. 
abrieron esta línea de investigación que ha resultado de mucho provecho sobre todo para la interpretación histórica de la Revolución Mexicana (1910-1917). ${ }^{1}$ Hasta entonces, la historiografía sostuvo que la renovación del catolicismo beligerante (denominado catolicismo social solo desde finales del siglo XIX) había resultado de la publicación de la encíclica Rerum Novarum de León XIII en 1891. Pero lo que evidencia el trabajo de Arrom es que esta "no fue el inicio de la movilización de los laicos católicos para proyectos sociales" (p. 74), pues los hombres y mujeres de clase media y alta que se organizaron voluntariamente en la Sociedad de San Vicente demuestran que por lo menos 40 años antes ya había laicos comprometidos que trabajaban con pobres, obreros, encarcelados y enfermos, soportaban circunstancias políticas adversas y defendían ideales políticos muy bien definidos.

Esta pequeña pero muy bien organizada sociedad de paúles en México y su azaroso desarrollo le permitieron a Silvia Arrom revelar cosas todavía más importantes. La más interesante, sin duda, fue el modus operandi de las conferencias femeninas. Más allá de comprobar estadísticamente que la Asociación de Señoras de la Caridad superó en número de afiliados, gastos, impacto social, expansión geográfica y longevidad a la sociedad masculina, lo que resulta novedoso es la explicación histórica que la autora ofrece al respecto. Arrom afirma que la abismal diferencia no significó que los hombres fueran menos religiosos o filántropos, sino que fue "la práctica de la caridad [la que] se había asociado con el género" (p. 186), de tal suerte que a los hombres se les asoció con actividades de supervisión y financiamiento, mientras que a las mujeres con el trabajo de campo y el contacto directo y regular con los desfavorecidos. Podría parecer que Arrom echó mano únicamente de la tesis de la complementariedad de los sexos y de la división sexual del trabajo para explicar la disparidad, pero no fue así. Ella postula inteligente y prudentemente que si bien "los mexicanos justificaron los nuevos roles de las mujeres con las concepciones de género tradicionales" (p. 174), con lo que hacían parecer que el trabajo social que realizaban fuera de sus casas era una extensión de sus labores domésticas, lo cierto es que solo fue un modo de introducir la novedad sin romper la tradición. Es decir, esta justificación hacía "tolerable" el "nuevo tipo de activismo femenino" (p. 162) que incrementaba en las mujeres de clase media y alta

las destrezas, la confianza en sí mismas y la autoridad moral que derivan de tomar parte de una organización internacional, asistir a reuniones, hablar en público, ejercer el sufragio, ocupar

1. Véase Jorge Adame Goddard, El pensamiento político y social de los católicos mexicanos, 1867-1914 (México: Universidad Nacional Autónoma de México, Instituto de Investigaciones Históricas, 1981); Manuel Ceballos Ramírez, El catolicismo social: un tercero en discordia. Rerum Novarum, la "cuestión social" y la movilización de los católicos mexicanos (1891-1911) (México: El Colegio de México, 1991); Roderic Ai Camp, Cruce de espadas. Política y religión en México (México: Siglo XXI, 1998); Gabriela Aguirre Cristiani, ¿Una historia compartida?: Revolución Mexicana y catolicismo social, 1913-1924 (México: Instituto Mexicano de Doctrina Social Cristiana, 2008). 
cargos de responsabilidad, preparar informes, recolectar fondos y manejar presupuestos, diseñar servicios de asistencia e instaurarlas, reformar a los pobres y fortalecer el compromiso con los fieles (p. 167).

Silvia Arrom sostiene también que la desproporción entre las conferencias de hombres y mujeres se explica por una razón práctica. Los hombres tuvieron y encontraron "otras maneras de defender su fe, servir al bien común y reformar el mundo moderno" (p. 185), mientras que para las mujeres la Asociación significó el único camino permisible para contribuir a la mejora de su sociedad y luchar por su religión.

La última parte de la investigación de Arrom es la más rica en reflexión y, por tanto, es la más propositiva. Después de haber narrado por separado el origen y las vicisitudes de la conferencia masculina y la femenina, Arrom concluye que la Sociedad de San Vicente de Paúl fusiona en su organización elementos tradicionales y modernos. Se parecen y sus funciones llegan a asociarse con las cofradías del Antiguo Régimen, pero sus formas de registro de socias, beneficiados y colaboradores, así como sus informes y el control de gastos y ayudas, hablan de todos los elementos modernos que hicieron que sus prácticas caritativas ocuparan "un lugar de transición entre el tradicional socorro a los pobres y el catolicismo social plenamente desarrollado" (p. 280).

Por cuestiones metodológicas y por la naturaleza de las fuentes que utilizó, la autora dedicó gran parte de su análisis a aspectos estadísticos, que pueden llegar a ser abrumadores en gran parte del libro. Sin embargo, la meticulosidad con la que fueron elaboradas las tablas y gráficas, así como el señalamiento de vacíos, pérdidas, variaciones u omisiones de los reportes, servirán de base para acercamientos regionales posteriores y tal vez para despertar nuevas preguntas. Lo único que queda faltando es un análisis más profundo de las instrucciones pastorales que prometen ser una fuente insoslayable en el desarrollo del activismo político de los católicos mexicanos. Puede ser que en la necesidad de subrayar la autonomía de la Asociación de San Vicente de Paúl respecto de la jerarquía eclesiástica, Silvia Arrom haya decidido no enfatizar sus vínculos. No obstante, considero que estos no le quitarían preeminencia a los voluntarios laicos y, mucho menos, importancia a las actividades y al grado de participación de las mujeres en las conferencias. Al contrario, mostrarían otro ángulo de las negociaciones y evidenciarían otro tipo de transformaciones y continuidades en la sociedad y en la práctica política.

Este trabajo será un nuevo punto de referencia historiográfico para el siglo XIX y para la historia de la Iglesia, de las instituciones de asistencia pública, de las mujeres y de la trasformación de las prácticas asociativas de los mexicanos. Su traducción al castellano tan solo un año después de su publicación en inglés (2016) ayudará a su circulación y discusión en México y América Latina. También, y más allá del contenido, el libro es un claro ejemplo de cómo una simpatía personal no obstaculiza un análisis académico serio y objetivo, sino que por el contrario lo puede generar y motivar. Solo una advertencia nos hace la autora en tan personal revelación: que nuestra ínfima experiencia de vida no limite las preguntas que le 
hacemos al pasado, ni obstruya la posibilidad de imaginar otros muchos mundos posibles, pues esto nos puede impedir "ver lo que teníamos ante los ojos, oculto a plena vista" (p. 301), pero que no podíamos dar a conocer porque nuestra curiosidad estaba interesada en explicar otro tipo de fantasías.

DOI: 10.17533/udea.trahs.n13a08 